\title{
MAKING SPATIAL STATISTICS SERVICE ACCESSIBLE ON CLOUD PLATFORM
}

\author{
Xiaoy an $\mathrm{Mu}^{1}{ }^{1}{ }^{*}$, Jingy ang $\mathrm{Wu}^{1}{ }^{1}, \mathrm{Te} \mathrm{Li}^{1}{ }^{1}$, Ying Zhong ${ }^{1,}, \mathrm{Xiang} \mathrm{Gao}{ }^{1}$ \\ ${ }^{1}$ School of Resource and Environmental Science of Wuhan University, 129 LuoyuRoad, Wuhan 430079, China \\ *Corresponding author, E-mail: iccgs@whu.edu.cn
}

KEY WORDS: Web service, Cloud platform, Microsoft Windows Azure, Eigenvector-based spatial filtering, Regression analysis, DLL

\begin{abstract}
:
Web service can bring together applications running on diverse platforms, users can access and share various data, information and models more effectively and conveniently from certain web service platform. Cloud computing emerges as a paradigm of Internet computing in which dynamical, scalable and often virtualized resources are provided as services. With the rampant growth of massive data and restriction of net, traditional web services platforms have some prominent problems existing in development such as calculation efficiency, maintenance cost and data security. In this paper, we offer a spatial statistics service based on Microsoft cloud. An experiment was carried out to evaluate the availability and efficiency of this service. The results show that this spatial statistics service is accessible for the public conveniently with high processing efficiency.
\end{abstract}

\section{INTRODUCTION}

Web service can bring together applications running on diverse platforms, enable database information exchange and allow applications originally meant for internal use be made available through the Internet (Christopher Ferris \& Joel Farrell 2003). Cloud computing emerges as a paradigm of Internet computing in which dynamical, scalable and often virtualized resources are provided as services. With the rampant growth of massive data and restriction of net, traditional web services platforms have some prominent problems existing in development such as calculation efficiency, maintenance cost and data security. To solve these problems, individual applications and enterprise storage are being deployed on clouds. By deploying service in the cloud, such infrastructure as storage and networks, which needs to be supplied by the developer in a traditional host-client pattern, is now available through the Internet from any where.

In this paper, we propose some spatial statistics services such as matrix operations service, statistical calculation service and regression analysis service. Integrating these services, we report an effort to develop a service system providing eigenvector-based spatial filtering (ESF) method to perform regression analysis with spatial data. This ESF service system makes users access to the powerful regression method by provisioning a serial of concerned services with the support of cloud computing.With these services, users can efficiently and conveniently perform regression analy sis with their own spatial data. Microsoft Windows Azure is chosen as the platform to develop and deploy these services and the ESF service system. Microsoft Windows Azure actually consists of a variety of different services on top of a common platform and it supports applications built on the .NET Framework and other popular programming languages supported in Windows systems (Zhang et al., 2010). Azure is selected as the platform for the ESF service due to our familiarity with the .NET framework and the development tools. Azure provides the full range services for developing the ESF system that takes advantage of parallel computing and easy access of the Web.

The remainder of this paper is arranged as follows: the second section analy zes the algorithm of ESF. Section three designs the service system and Web page layout. Subsequently, an experiment is presented to demonstrate the availability and accessibility of these services and the accuracy of the eigenvector-based spatial filtering regression model.

\section{ANALYS IS OF ESF ALGORITHM}

Ordinary Least Square (OLS) is a commonly used method in regression analysis. However, when dealing with spatial data, the existence of spatial autocorrelation often leads to violations of the basic assumptions for OLS (Tobler, 1970; Hubert et al., 1981; Getis, 1990).The eigenvector-based spatial filtering (ESF) service provides an effective spatial regression model to handle with spatial autocorrelations. The effect of the variables in the regression model is divided into two parts: spatial influence and non-spatial influence. Extracting the spatial influence part and filtering it, then we can use the basic method to make regression analy sis.

About the first author: Mu Xiaoyan, E-mail: iccgs@ @hu.edu.cn 


\subsection{ESF algorithm process}

(1) Generate the spatial connectivity matrix.

(2) Calculate the eigenvalue and eigenvector of the connectivity matrix.

(3) Select eigenvectors as spatial filters.

(4)Perform Ordinary Least Square regression analy sis with the original explanatory variables and the selected eigenvectors.

(5)Assess the quality of the model.

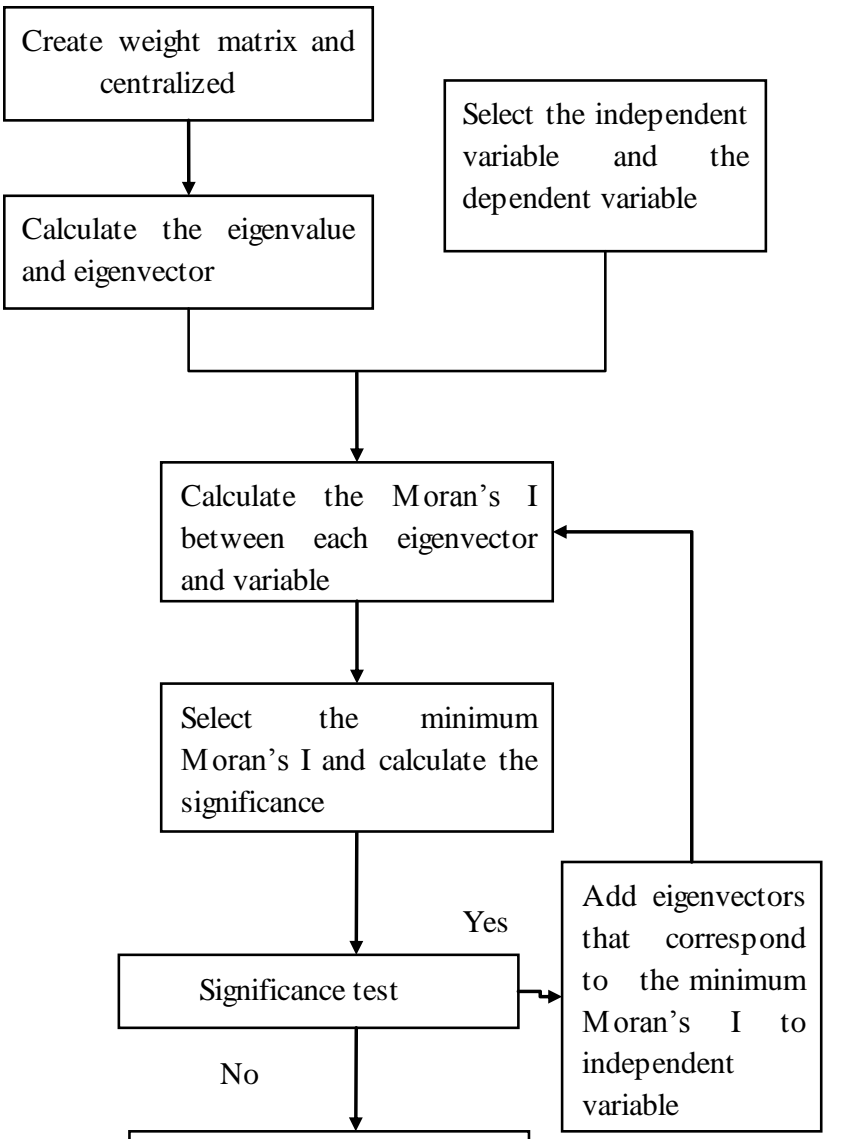

Process variables with least square method

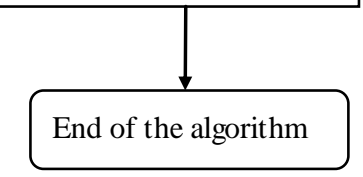

Figure 1. Algorithm flow diagram

\subsection{The concrete implementation of the ESF algorithm}

Component Object Model (COM) from Microsoft is one of the mature component technologies and widely employed in its operating system and application software. Component technology is a powerful and hot scheme to actualize software reuse, shorten programming time, decrease maintenance costs and realize dy namic program up grade.

Dynamic Link Library (DLL) provides a convenient way to share data and code. It can save disk space significantly for different applications can share the same DLL function. Various of programming tools can be implemented to write DLL files such as $\mathrm{vc}++, \mathrm{c}++$ Builder and Delph.

Eigenvector-based spatial filtering algorithm is written with COM technology in Microsoft Visual $\mathrm{C}++6.0$ environment. Then the corresponding DLLs are generated to be accessed dynamically at run time and invoked by the share service.

\subsubsection{The overall framework and functional module}

The ESF service system will be divided into four major modules: fundamental function module, matrix calculation module, statistical computing module and regression calculation module. There are four classes according to the module division. The fundamental functional class is not required as the interface exposed to the users, so it is a fundamental class while the other three classes are the interface classes. The next section will give detailed descriptions of these classes.

\subsubsection{The design of the class}

(1) CComBase is a common class to achieve fundamental functions. It contains some functions for the subsequent calculation.

(2) CmatrixBase is a class for matrix operations, and ultimately exposed to the user with the form of interface. Users can invoke external without understanding details of its implementation. The interfaces and functions are shown in table 1.

\begin{tabular}{|c|c|}
\hline Interface Name & Interface function \\
\hline Create_Weight & Create weight matrix \\
\hline Weight_Centered & Center weight matrix \\
\hline Variable_Centered & Center variables \\
\hline Transpose_Matrix & Calculate transpose matrix \\
\hline Save_Matrix & Storage matrix \\
\hline Normal_Matrix & Calculate normal matrix \\
\hline Merge_Matrix & Merge matrixes \\
\hline Inverse_Matrix & Calculate inverse matrix \\
\hline Dsyevr_Eigen & Calculate the eigenvalue and eigenvector \\
\hline
\end{tabular}

Table 1. Introduction for the CmatrixBase interface and function (3) Cstatistic is an interface class for statistical computing function. It implements intermediary step of the ESF algorithm and can be invoked by users. The interfaces and functions are shown in table 2 .

\begin{tabular}{|c|c|}
\hline Interface Name & Interface function \\
\hline Hat_Matrix & Calculate hat matrix \\
\hline Cal_Residual & Calculate Residual \\
\hline Cal_MoranI & Calculate Moran's I \\
\hline OLS_Regression & Ordinary Least Square Regression \\
\hline
\end{tabular}

Table 2. Introduction for the Cstatistic interface and function (4)Ceigenfunction is an interface class for regression computing. It is important step of the ESF algorithm and can be invoked by users. The interfaces and functions are shown in table 3. 


\begin{tabular}{|c|c|}
\hline Interface Name & Interface function \\
\hline ReadFieldsName & Get attribute names \\
\hline Simple_ratio & $\begin{array}{c}\text { Choose eigenvector with Simple_ratio } \\
\text { method }\end{array}$ \\
\hline Step_wiseV & $\begin{array}{c}\text { Choose eigenvector with Step_wise } \\
\text { method }\end{array}$ \\
\hline Regression & Regression analy sis \\
\hline
\end{tabular}

Table 3. Introduction for the Ceigenfunction interface and function

\subsubsection{The generation of DLL}

Build function framework for COM component according to the system structure designed in the previous section in visual $\mathrm{c}++$ 6.0. So we can have more clearly organized to write code. After the completion of code editor, click the DLL generation button in the Build TAB, then complete the generation of a DLL. Users can invoke the interface functions in other programs after registering the DLL on their computers.

\section{RES EARCH OF ESF S ERVICE S YS TEM}

\subsection{The system design of ESF service}

Making DLL component function in to web service, and then deploy the web service on cloud platform for users to access. Edit the web service interface for invoke to achieve the function of regression analy sis.

Specific implementation process is shown in figure 2 .

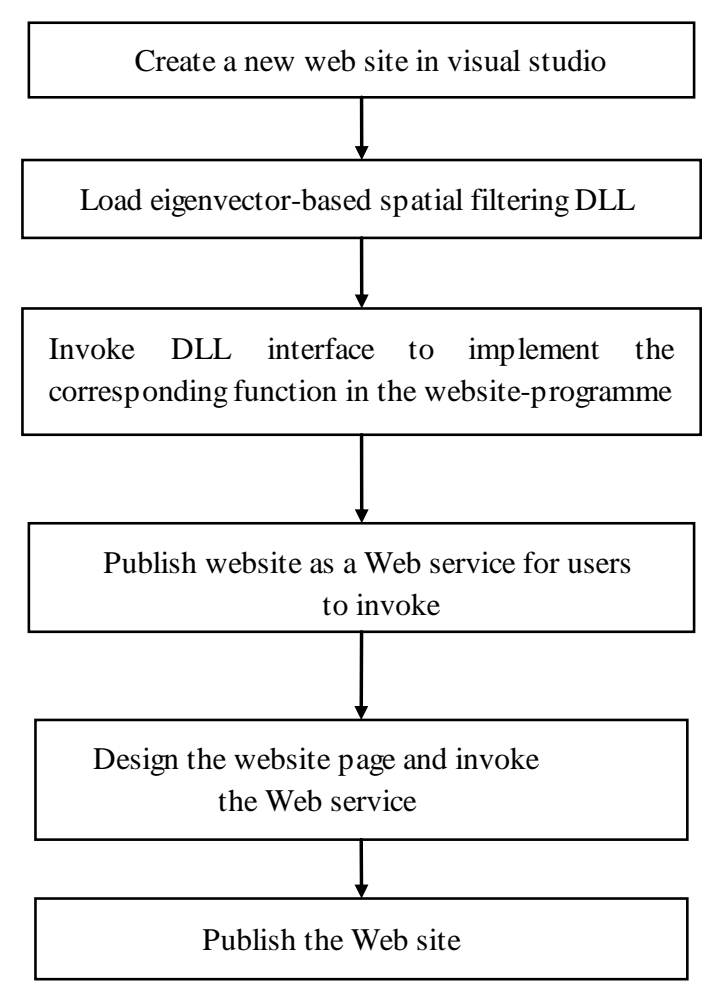

Figure 2.Web service process
ESF service system is a more complete service system, including user management, document management and data processing and other functions. Service architecture is shown in figure 3.

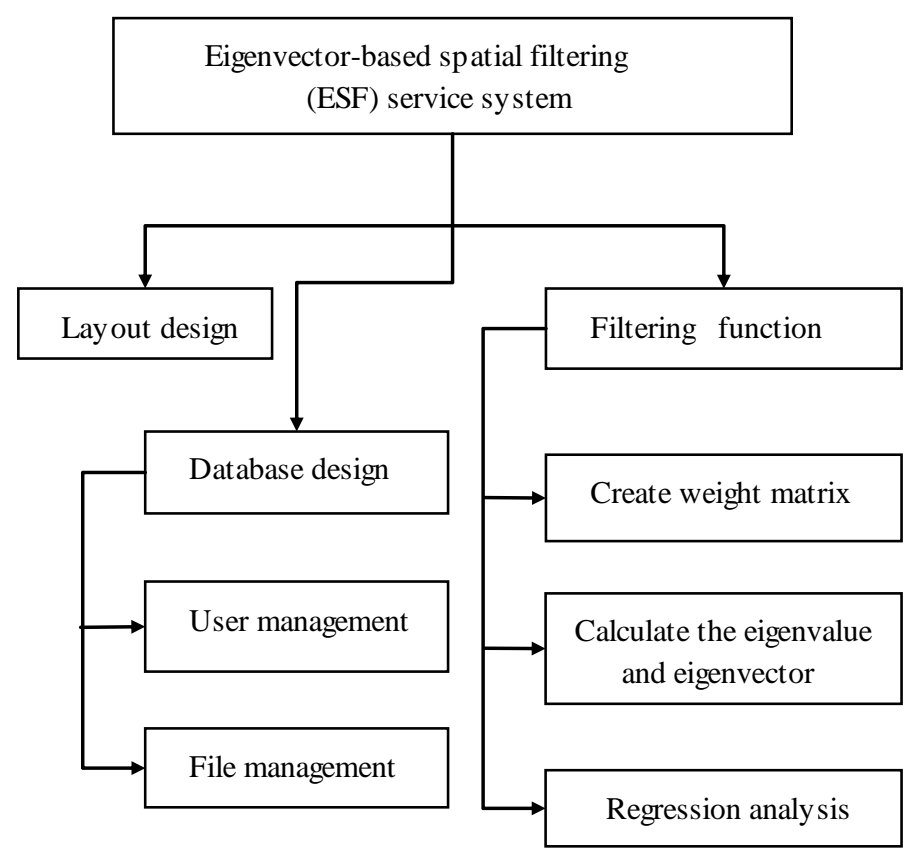

Figure 3. Service architecture

\subsection{The service design of ESF service}

Use ASP.NET to compile ESF algorithm DLL into the Web Service interface in the Microsoft Visual Studio 2010 environment. And then invoke the web service in website to allow the users to complete regression analysis. The main interfaces and functions are shown in table 4.

\begin{tabular}{|c|c|}
\hline Interface Name & Interface function \\
\hline Cal_MoranI & Calculate M oran's I \\
\hline CalculateEigen & Calculate the eigenvalue and eigenvector \\
\hline Hat_Matrix & Calculate hat matrix \\
\hline OLS_Regression & Ordinary Least Square Regression \\
\hline RegressionModel & Regression analy sis \\
\hline createWFilebyShp & Add attributes to DBF database \\
\hline getDBFfieldName & Get DBF attribute name \\
\hline simpleSelect & Simple selection method to choose \\
& eigenvector \\
\hline
\end{tabular}

Table 4. Introduction for web service interface and function 


\subsection{The website design of the service}

We create two websites (web service website and ESF service website which integrates related web services) considering that users may need one or more services.

The name of the interface corresponds to its function in the web service website. Each web service has some brief instructions on the interface so that users can have a clearly understanding of its use.

\section{staService}

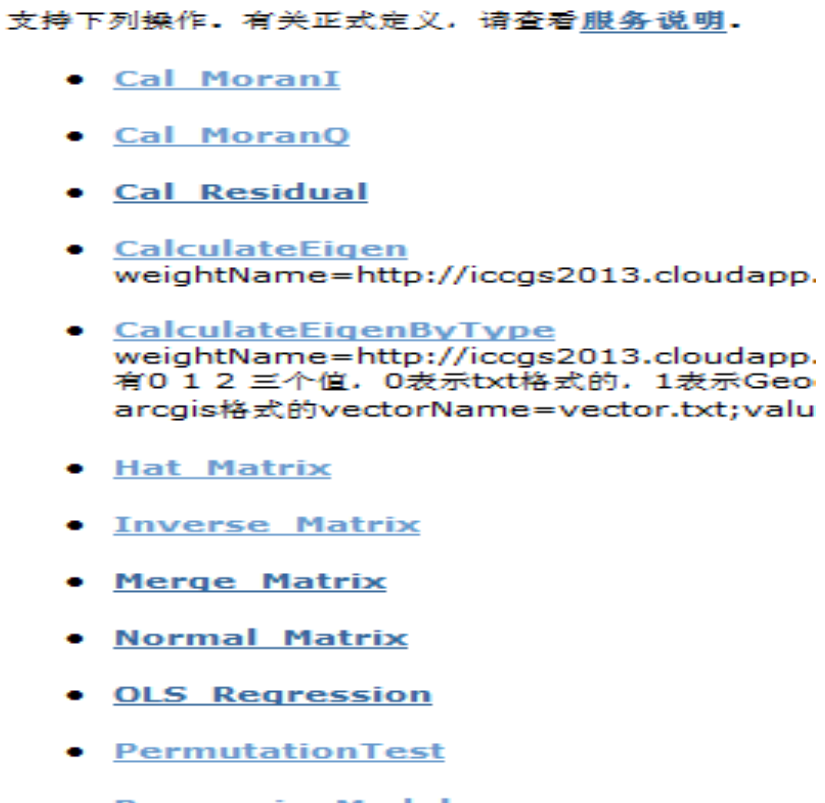

- RegressionModel

\section{staService}

\section{年击此处. 英取宅整的作列表.}

\section{CalculateEigen}

观到

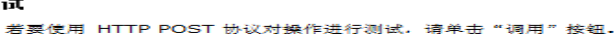

数 但

user:

WFilename:

vectorName: valueName:

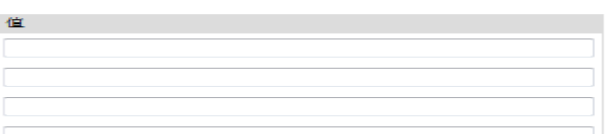

Figure 4. Web service site

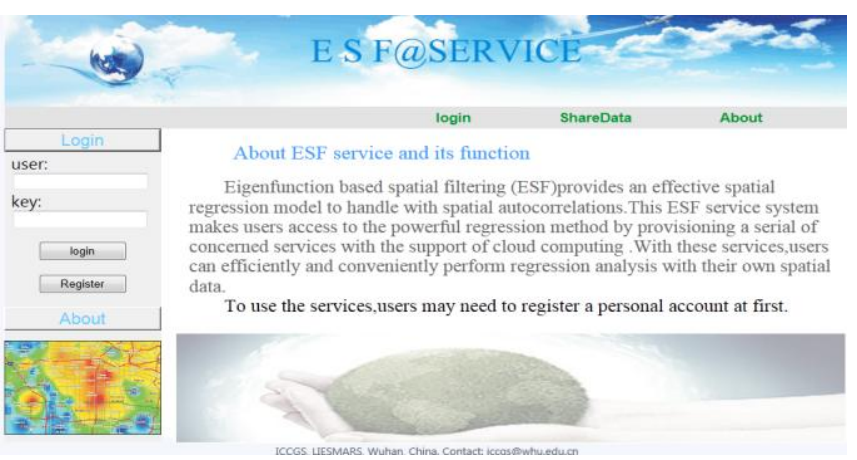

Figure 5. The portal site of ESF service sy stem

\section{EXPERIMENT}

\subsection{Experiment data}

Data content: Economic development status and other basic attributes about thirty provinces of Chinese.

The Data used in the experiment contains the dependent variable GDP and independent variable AREA and Pop .

The detailed data is shown in figure 6 .

\begin{tabular}{|c|c|c|c|c|c|c|c|c|}
\hline \multicolumn{2}{|r|}{ F1 } & \multicolumn{2}{|c|}{ - $\left(\begin{array}{ll|l}1 & f_{x} & \mathbb{N A N E} \\
\end{array}\right.$} & \multirow[b]{2}{*}{ E } & \multirow[b]{2}{*}{ F } & \multirow[b]{2}{*}{ G } & \multirow[b]{2}{*}{ H } & \multirow[t]{2}{*}{ v } \\
\hline 1 & B & C & D & & & & & \\
\hline 1 & PERINETER & AREA & ADCODE93 & ADCODE99 & NAME & GDP & \begin{tabular}{|l|} 
Pop \\
\end{tabular} & SFILTER \\
\hline 2 & 68.489 & 54.447 & 230000 & 230000 & 黑龙江省 & 8257.24000 & 3824 & 685.2867000 \\
\hline 3 & 129.933 & 129.113 & 150000 & 150000 & 内蒙古自治区 & 8967.52000 & 2405 & 619.2514000 \\
\hline 4 & 84.905 & 175.591 & 650000 & 650000 & 新疆维吾尔自治区 & 4005.41000 & 2095 & -478.6630000 \\
\hline 5 & 41.186 & 21.315 & 220000 & 220000 & 吉林省 & 7072.25000 & 2730 & 918.8021000 \\
\hline 6 & 38.379 & 15.603 & 210000 & 210000 & 辽宁省 & 14696.20000 & 4298 & 870.5908000 \\
\hline 7 & 76.781 & 41.508 & 620000 & 620000 & 甘肃省 & 3373.78000 & 2619 & -616.7130000 \\
\hline 8 & 44.874 & 19.504 & 130000 & 130000 & 河北省 & 17068.00000 & 6943 & 505.5459000 \\
\hline 9 & 8.498 & 1.733 & 110000 & 110000 & 北京市 & 11469.30000 & 1633 & 484.3685000 \\
\hline 10 & 24.784 & 15.961 & 140000 & 140000 & 山西省 & 7050.38000 & 3393 & $-49.9480000=$ \\
\hline 11 & 7.263 & 1.214 & 120000 & 120000 & 天津市 & 7068.56000 & 1115 & 484.3685000 \\
\hline 12 & 38.571 & 20.394 & 610000 & 610000 & 陕西省 & 7752.20000 & 3748 & -788.9350000 \\
\hline 13 & 18.520 & 5.272 & 640000 & 640000 & 宁夏回族自治区 & 1198.15000 & 610 & -166.7250000 \\
\hline 14 & 59.562 & 71.363 & 630000 & 630000 & 青海省 & 1012.69000 & 552 & -631.0060000 \\
\hline 15 & 40.900 & 15.388 & 370000 & 370000 & 山东省 & 33621.30000 & 9367 & -557.2750000 \\
\hline 16 & 76.629 & 114.331 & 540000 & 540000 & 西藏自治区 & 434.34000 & 284 & -389.6980000 \\
\hline 17 & 30.911 & 16.135 & 410000 & 410000 & 河南省 & 19724.70000 & 9360 & -803.6700000 \\
\hline 18 & 27.893 & 9.736 & 320000 & 320000 & 江苏省 & 33478.80000 & 7625 & -593.4000000 \\
\hline 19 & 29.492 & 13.365 & 340000 & 340000 & 安微省 & 10191.50000 & 6118 & -960.365000 \\
\hline 20 & 58.636 & 45.534 & 510000 & 510000 & 四川省 & 14050.80000 & 8127 & -567.9730000 \\
\hline 21 & 34.321 & 17.563 & 420000 & 420000 & 湖北省 & 12866.00000 & 5699 & -673.123000 \\
\hline 22 & 26.012 & 7.716 & 510000 & 500000 & 重庆市 & 5693.58000 & 2816 & -224.9980000 \\
\hline 23 & 26.825 & 9.277 & 330000 & 330000 & 浙江省 & 22717.00000 & 5060 & -336.8220000 \\
\hline 24 & 32.801 & 19.390 & 430000 & 430000 & 湖南省 & 12939.80000 & 6355 & 597.3233000 \\
\hline 25 & 26.668 & 15.277 & 360000 & 360000 & 汀西省 & 6954.12000 & 4368 & 12.6938000 \\
\hline
\end{tabular}

Figure 6. Experiment data

\subsection{The experiment process}

\subsubsection{Upload personal data}

To use these services, users may need to register a personal account at first. After the success of the registration, you can upload spatial data to the server side for spatial statistics service. In the individual data centre, practical directory services including file selection, file deletion, file downloading and file sharing are provided for the convenience of data management.

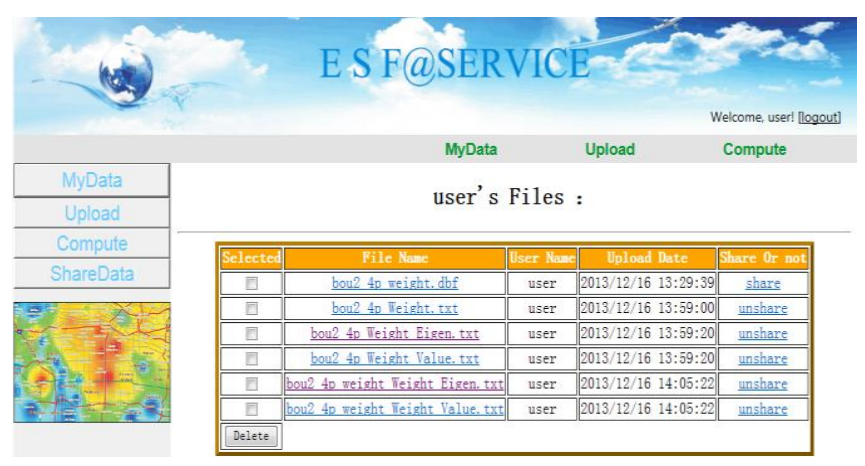

Figure 7. Personal data center 
4.2.2 Generate spatial connectivity matrix by shp
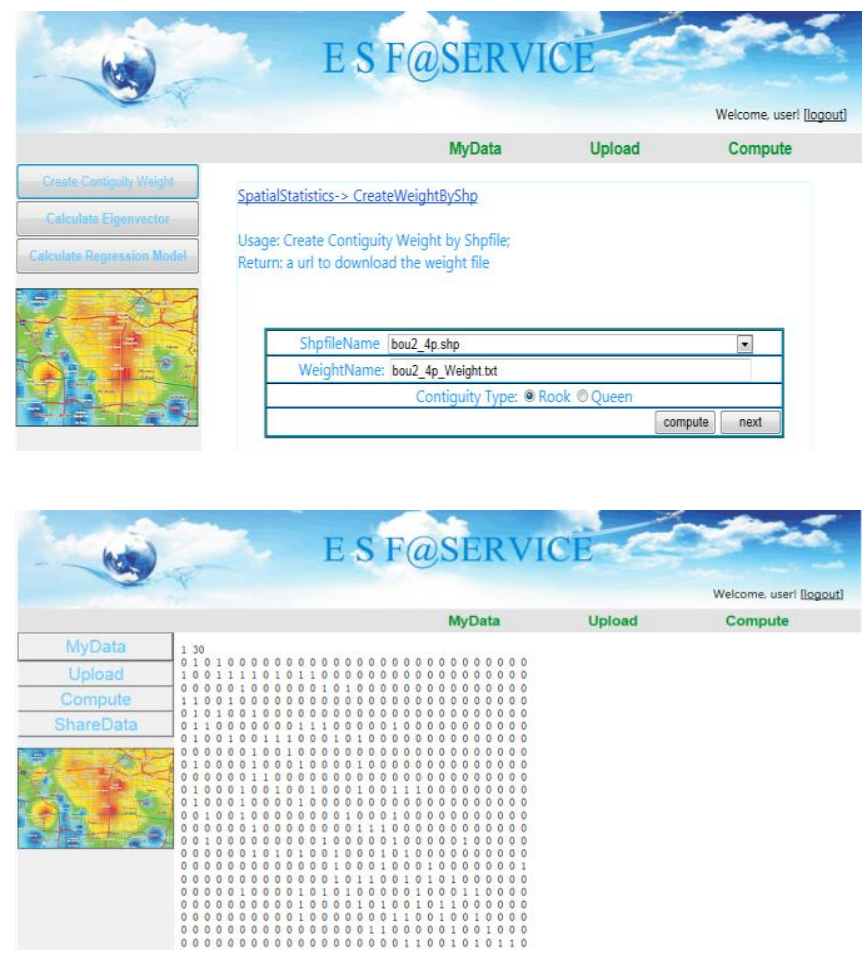

Figure 8 . The result of connectivity matrix

\subsubsection{Calculating the eigenvalue and eigenvector}
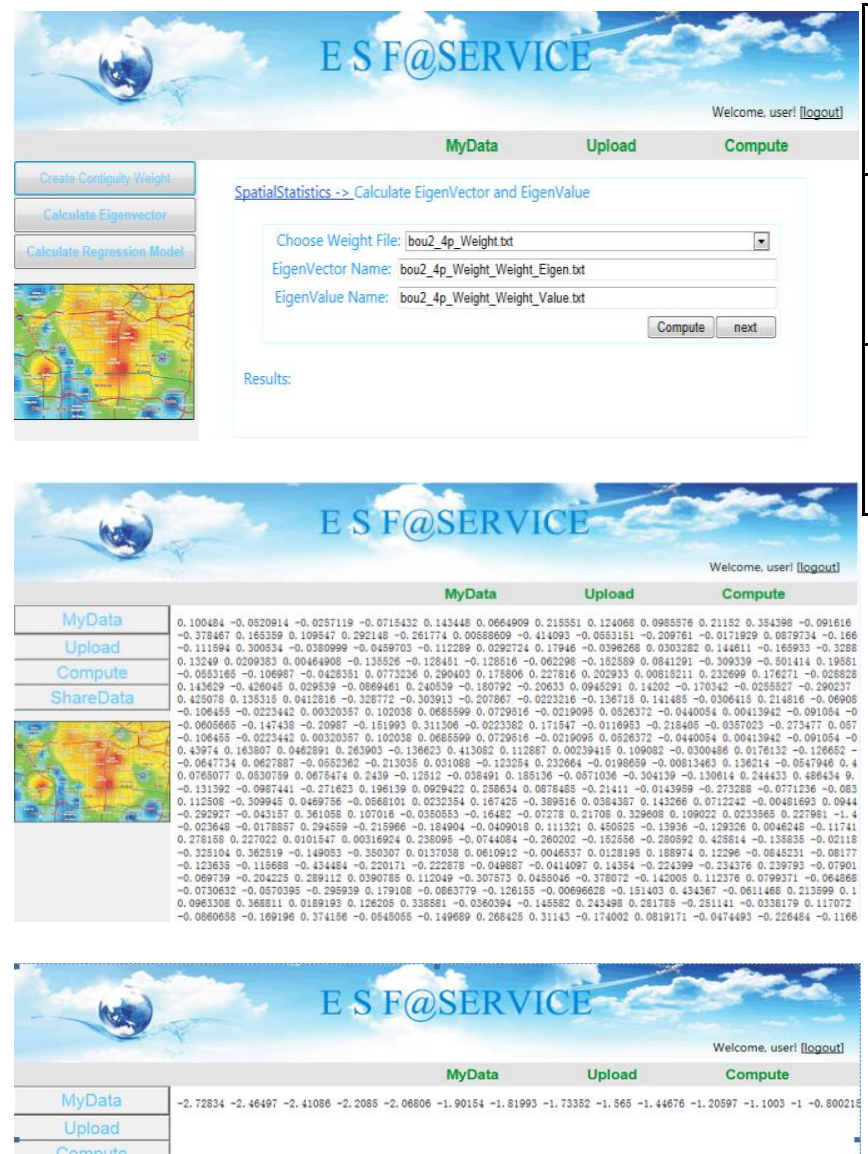

\begin{tabular}{|c|c|c|c|c|c|c|}
\hline & $\mathrm{Y}$ & X & $\begin{array}{c}\text { Numb } \\
\text { ers of } \\
\text { Select } \\
\text { eigen }\end{array}$ & R-squared & $\begin{array}{l}\text { Adjusted } \\
\text { R-squared }\end{array}$ & $\begin{array}{l}\text { Akaike } \\
\text { info } \\
\text { criterion }\end{array}$ \\
\hline $\begin{array}{c}\text { Geo } \\
\text { da- } \\
\text { Clas } \\
\text { sic }\end{array}$ & $\begin{array}{l}\mathrm{G} \\
\mathrm{D} \\
\mathrm{P}\end{array}$ & $\begin{array}{l}\text { AR } \\
\text { EA } \\
\text { Pop }\end{array}$ & & 0.640175 & 0.613521 & 609.068 \\
\hline $\begin{array}{c}\text { ESF } \\
- \\
\text { Sim } \\
\text { ple }\end{array}$ & $\begin{array}{l}\mathrm{G} \\
\mathrm{D} \\
\mathrm{P}\end{array}$ & $\begin{array}{l}\text { AR } \\
\text { EA } \\
\text { Pop }\end{array}$ & 8 & 0.838517 & 0.753526 & 580.476 \\
\hline
\end{tabular}

From the friendly user and result interfaces showed above, it can be seen that ESF service is accessible for the public conveniently with high processing efficiency. In addition, deployed on Microsoft cloud, these spatial statistics services can be remote accessed by entering website in to browser address bar wherever and whenever.

\subsection{Comparision of different regression results}

Area, population and GDP of each province are selected as experiment data. Perform regression analysis with this data respectively in Geoda software and ESF system. The different regression results are shown in table 5.
Table 5. Regression results in different software Illustration: Geoda - Classic: regression result with Geoda software; ESF - Simple (simple ratio to choose eigenvector): regression result with ESF system.

In all the regressions, four parameters are calculated to assess the quality of those models. For the convenience of comparison, the significant tests for regression equation and regression parameters are not listed here. Among those parameters, both Rsquared and Adjusted R-squared are used to test the goodness of fit of the regression model. A low number means worse fitting degree while higher numbers means good fit degree. Akaike info criterion is used to test the accuracy of the regression model. A low number means good accuracy while higher numbers means worse.

Figure 9. The result of eigenvector and eigenvalue 
Result: As displayed in the table above, ESF service system has better fitting degree than Geoda software and improves the accuracy of the regression model.

\section{CONCLUSION}

This paper proposed an ESF service system and some statistics services based on a cloud platform, Windows Azure. By deploying the system on the cloud, the availability and accessibility of these services have been significantly improved. With this system, users can conveniently get access to the spatial filtering method and use those services to analyze spatial data efficiently. Eigen function based spatial filtering method can eliminate the spatial autocorrelation to some extent and improve the accuracy of the regression model.

\section{ACKNOWLEDGEMENT}

The research is supported by grants from National Nature Science Foundation of China (project No. 41171347).

\section{REFERENCES}

[1] Zhang, Q., Cheng, L., \& Boutaba, R. (2010). Cloud computing: state-of-the-art and research challenges. Journal of Internet Services and Applications, 1(1), 7-18.

[2] Kun, Y.,WANG, X., \& ZHOU, R. (2004). Underlying Techniques for Web Services: A Survey. Journal of Software, Vol.15, No.3.

[3] Huhns, M.N., Singh, M.P. (2005). Service-oriented computing: key concepts and principles. IEEE Internet Computing, vol. 09, pp. $75-81$.

[4] Ferris,C., Farrell, J. (2003). What are Web Services? Communications of the ACM, vol. 46, No.6 pp. 31.

[5] Tobler, W. R. (1970). A computer movie simulating urban growth in the Detroit region. Economic Geography, 46(2), 234-240.

[6] Hubert, L. J., Golledge, R. G., \& Costanzo, C. M. (1981). Generalized procedures for evaluating spatial autocorrelation. Geographical Analysis, 13(3), 224-233.

[7] Getis, A. (1990). Screening for spatial dependence in regression analy sis. Papers in Regional Science, 69(1), 69-81.

Griffith, D. A. (2000). A linear regression solution to the spatial autocorrelation problem. Journal of Geographical Systems, 2(2), 141-156.

[8] Griffith, D. A., \& Peres-Neto, P. (2006). Spatial modeling in ecology: the flexibility of eigenfunction spatial analyses. Ecology, 87(10), 2603-2613.

[9] Fox, A., Griffith, R., Joseph, A., Katz, R., Konwinski, A., Lee, G., ... \& Stoica, I. (2009). Above the clouds: A Berkeley view of cloud computing. Dept. Electrical Eng. and Comput. Sciences, University of California, Berkeley, Rep. UCB/EECS, 28.
[10] Johnston, S. J., O’Brien, N. S., Lewis, H. G., Hart, E. E., White, A., \& Cox, S. J. (2013). Clouds in space: Scientific computing using windows azure. Journal of Cloud Computing, 2(1), 1-10.

[11] Molto, G., Calatrava, A., \& Hernandez, V. (2013). A Service-Oriented Architecture for Scientific Computing on Cloud Infrastructures. In M. Dayde, O. Marques, \& K. Nakajima (Eds.), VECPAR 2012 (pp. 163-176). Berlin: Springer.

[12] Shiraz, M., Abolfazli, S., Sanaei, Z., \& Gani, A. (2013). A study on virtual machine deployment for application outsourcing in mobile cloud computing. The Journal of Supercomputing, 63(3), 946-964.

[13] Höfer, C. N., \& Karagiannis, G. (2011). Cloud computing services: taxonomy and comparison. Journal of Internet Services and Applications, 2(2), 81-94. 